\title{
Droplets heating and evaporation: an application to diesel-biodiesel fuel mixtures
}

\author{
Mansour al Qubeissi¹ ${ }^{\star 1}$ Nawar Al-Esawi ${ }^{1}$, Sergei S. Sazhin ${ }^{2}$ \\ ${ }^{1}$ Centre for Mobility and Transport, Faculty of Engineering, Environment and Computing, \\ Coventry University, Coventry CV1 2JH, UK \\ ${ }^{2}$ Advanced Engineering Centre, School of Computing, Engineering and Mathematics, \\ University of Brighton, Brighton BN2 4GJ, UK \\ *Corresponding author: mansour.qubeissi@coventry.ac.uk
}

\begin{abstract}
The heating and evaporation of automotive fuel droplets are crucial to the design of internal combustion engines and to ensuring their good performance. Accurate modelling is essential to the understanding of these processes and ultimately improving engine design. The interest in fossil-biodiesel fuel blends has been mainly stimulated by depletion of fossil fuels and the need to reduce carbon dioxide emissions that contribute towards climate change. This paper presents an analytical investigation into the application of discrete component model for the heating and evaporation of multi-component fuel droplets to several blended diesel-biodiesel fuels. The model considers the contribution of all groups of hydrocarbons in diesel fuel and methyl esters in biodiesel fuels. The main features of new application to the analysis of blended-fuel droplets in engine-like conditions is described. The model is applied to several blends of diesel, combining 98 components of hydrocarbons, and 19 types biodiesel fuels, combining up to 17 species of methyl ester, considering the differences in their chemical levels of saturation, and thermodynamic and transport properties. One important finding is that some fuel blends, e.g. B5 (5\% biodiesel fuel and 95\% diesel fuel), can give almost identical droplet lifetimes to the one predicted for pure diesel fuel; i.e. such mixtures can be directly used in conventional diesel engines with minimal, or no, modification to the droplet break-up process.
\end{abstract}

\section{Keywords}

Biodiesel, Diesel, Fuel droplet, Fuel mixture, Heating and evaporation

\section{Introduction}

Renewable sources of energy, such as biodiesel fuels, have been of great interest to scientists and public in the last decades due to depletion of fossil fuels and impact on global warming [1,2]. Also, compared to fossil fuel, biodiesel fuel has several advantages: it has less carbon dioxide emissions, higher flash point, higher lubricity and it is cost effective; in addition, the blend of diesel-biodiesel fuels can be used in diesel engines with minimal/no modifications $[3,4]$.

The delay in processes preceding the onset of combustion (mainly the heating and evaporation of fuel droplets) in the internal combustion engines is crucial to the design and performance of these engines [5,6]. However, the complexity of modelling these processes should be taken into account as it involves detailed physics of heat transfer, mass transfer and fluid dynamics associated processes.

In this paper, the discrete component model (DCM) (see [5-7]) is utilised to analyse the droplets heating and evaporation of diesel-biodiesel fuel blends.

These blends are represented by a mixture of 19 types of biodiesel fuels with up to 17 species of methyl ester (see [8] for more details) and diesel fuel, formed of 98 hydrocarbons (see [7] for more details). The thermodynamic and transport properties of diesel fuel are inferred from [7]; while for properties of biodiesel fuel are taken from [9]. The contribution of species and average droplet temperatures are taken into account in the calculation of all properties in the liquid phase. The vapour mixtures are treated as ideal gases.

\section{Model and fuel compositions}

Following $[10,11]$, the analysis of droplets heating and evaporation processes is made in application to several blends of diesel and biodiesel fuels. In contrast to previous approaches, the discrete component model (DCM) (described in [5,12] and validated experimentally in [13]) is used for this analysis; and the model is applied to a broad range of diesel-biodiesel fuel fractions. The mixture of EU diesel fuel with 19 types of widely used biodiesel fuels have been investigated. These are: Tallow Methyl Ester (TME), Lard Methyl Ester (LME), Butter Methyl Ester (BME), Coconut Methyl Ester (CME), Palm Kernel Methyl Ester (PMK), Palm Methyl Ester (PME), Safflower Methyl Ester (SFE), Peanut Methyl Ester (PTE), Cottonseed Methyl Ester (CSE), Corn Methyl Ester (CNE), Sunflower 
Methyl Ester (SNE), Soybean Methyl Ester (SME), Rapeseed Methyl Ester (RME), Linseed Methyl Ester (LNE), Tung Methyl Ester (TGE), Hemp-oil Methyl Ester, produced from Hemp seed oil in Ukraine (HME1), Hemp-oil Methyl Ester, produced in European Union (HME2), Canola seed methyl ester (CAN) and Waste cooking-oil Methyl Ester (WCO). Droplets with four fractions of diesel-biodiesel blends have been investigated in the DCM; these are 5\% biodiesel with $95 \%$ diesel fuels (B5), $20 \%$ biodiesel with $80 \%$ diesel fuels (B20), $50 \%$ biodiesel with $50 \%$ diesel fuels (B50), pure biodiesel (B100) and pure diesel fuels (PD).

The DCM is based on the analytical solutions to the heat transfer and species diffusion equations via the Effective thermal conductivity model (ETC) and Effective Diffusivity model (ED). The importance of these models can be attributed to the fact that they take into account the recirculation, temperature gradients and species diffusion inside droplets.

The heat conduction equation for the temperature $T=T(t, R)$ in the liquid phase in a spherical droplet can be presented as:

$$
\frac{\partial T}{\partial t}=\kappa\left(\frac{\partial^{2} T}{\partial R^{2}}+\frac{2}{R} \frac{\partial T}{\partial R}\right)
$$

where $\kappa=k_{e f f} / \rho_{l} c_{l}$ is liquid thermal diffusivity, $k_{e f f}, \rho_{l}$ and $c_{l}$ are the effective thermal conductivity, liquid density, and liquid specific heat capacity, respectively, $R$ is the distance from the centre of the droplet (assumed to be spherical), $t$ is time. $k_{\text {eff }}$ is linked with the liquid thermal conductivity $k_{l}$ via the following equation [14]:

$$
k_{\text {eff }}=\chi k_{l} \text {, }
$$

where $\chi$ is the coefficient of recirculation, which varies between 1 and 2.72 (see [15] for details about the calculation of this coefficient).

The diffusion of mass fractions $\left(Y_{l i}\right)$ of liquid species $i$ in a spherical droplet is described by the following equation:

$$
\frac{\partial Y_{l i}}{\partial t}=D_{\text {eff }}\left(\frac{\partial^{2} Y_{l i}}{\partial R^{2}}+\frac{2}{R} \frac{\partial Y_{l i}}{\partial R}\right)
$$

where the diffusion coefficient of liquid species is linked with the liquid diffusion coefficient by the following equation of the Effective Diffusivity (ED) model [6,11]:

$$
D_{\text {eff }}=\chi_{Y} D_{l}
$$

where $\chi$ is the recirculation coefficient for species diffusion. The analysis of droplets evaporation is based on the following expression:

$$
\dot{m}_{d}=-2 \pi R_{d} D_{v} \rho_{\text {total }} B_{M} \mathrm{Sh}_{\mathrm{iso}},
$$

where $D_{v}$ is the binary diffusion coefficient of vapour in gas (air), $\rho_{\text {total }}=\rho_{g}+\rho_{v}$ is the total density of mixture of gas and vapour, $B_{M}$ is the Spalding mass transfer number:

$$
B_{M}=\frac{\rho_{v s}-\rho_{v \infty}}{1-\rho v s}=\frac{Y_{v s}-Y_{v \infty}}{1-Y v s}
$$

$Y_{v}$ are the vapour mass fractions and $\rho_{v}$ are densities of vapour, in the vicinity of droplet surfaces $(s)$ and at a large distance from them $(\infty)$, respectively, $\mathrm{Sh}_{\mathrm{iso}}$ is the Sherwood number for isolated droplets defined as $[15,16]$.

$$
\mathrm{Sh}_{\mathrm{iso}}=2 \frac{\ln \left(1+B_{M}\right)}{B_{M}}\left[1+\frac{\left(1+\mathrm{Re}_{\mathrm{d}} \mathrm{Sc}_{d}\right)^{\frac{1}{3}} \max \left\{1, \mathrm{Re}_{d}^{0.077}\right\}-1}{2 F\left(B_{M}\right)}\right] \text {, }
$$

where $\operatorname{Re}_{d}=\frac{2 \rho_{l} u_{s} R_{d}}{\mu_{l}}$ is the Reynolds number, $\mathrm{S}_{\mathrm{C}_{\mathrm{d}}}=\frac{v_{l}}{D_{l}}$ is the liquid Schmidt number, $v_{l}$ is the kinematic viscosity of liquid, and $u_{s}$ is the maximal liquid velocity near the surface of the droplet, calculated using the Abramzon and Sirignano [15] approach as:

$$
u_{S}=\frac{1}{32} \Delta u\left(\frac{\mu_{g}}{\mu_{l}}\right) \operatorname{Re}_{d} C_{F}
$$

where $\Delta u=\left|u_{g}-u_{d}\right|$ and $C_{F}=\frac{12.69}{\operatorname{Re}_{\mathrm{d}}^{2 / 3}\left(1+B_{M}\right)}$ is the drag coefficient, $u_{g}$ and $u_{d}$ are the gas and droplet velocities, respectively. The partial vapour pressure of species $i$ at the surface of the droplet is calculated based the following expression: 


$$
p_{v i s}=X_{l i s} \gamma_{i} p_{v i s}^{*}
$$

where $X_{\text {lis }}$ is the molar fraction of $i^{\text {th }}$ species in the liquid near the droplet surface, $\gamma$ is the activity coefficient and $p_{v i s}^{*}$ is the saturated vapour pressure of species (in the absence of other species).

The thermodynamic and transport properties are inferred from [7] for diesel fuel; while those for biodiesel fuel are inferred from previous calculations in [9]. All properties are averaged based on molar contribution of species and average droplet temperatures. The mixtures are treated as ideal gases. As in previous studies $[7,10,11]$, blended fuel vapour is assumed to diffuse from the surface of the droplet, without changing its composition, based on averaged binary diffusion of diesel fuel vapour into dry air.

\section{Results}

The discrete component model (DCM) described in the previous section is facilitated for the analysis of heating and evaporation of diesel-biodiesel fuel droplets of initial radius $R_{d 0}=12.66 \mu \mathrm{m}$ and temperature $T_{0}=360 \mathrm{~K}$. The droplets are moving at $10 \mathrm{~m} \mathrm{~s}^{-1}$ in still air of pressure and temperature equal to $30 \mathrm{bar}$ and $800 \mathrm{~K}$, respectively. This assumption is compatible with those used in [17].

The evolutions of droplet surface temperatures $\left(T_{s}\right)$ and radii $\left(R_{d}\right)$ for three mixtures of diesel-biodiesel fuels (B5, B20, B50) and pure biodiesel fuel (B100) of 19 types of biodiesel fuels are analysed. Figures 1-6 show some typical examples of the analysed blends of diesel-biodiesel.

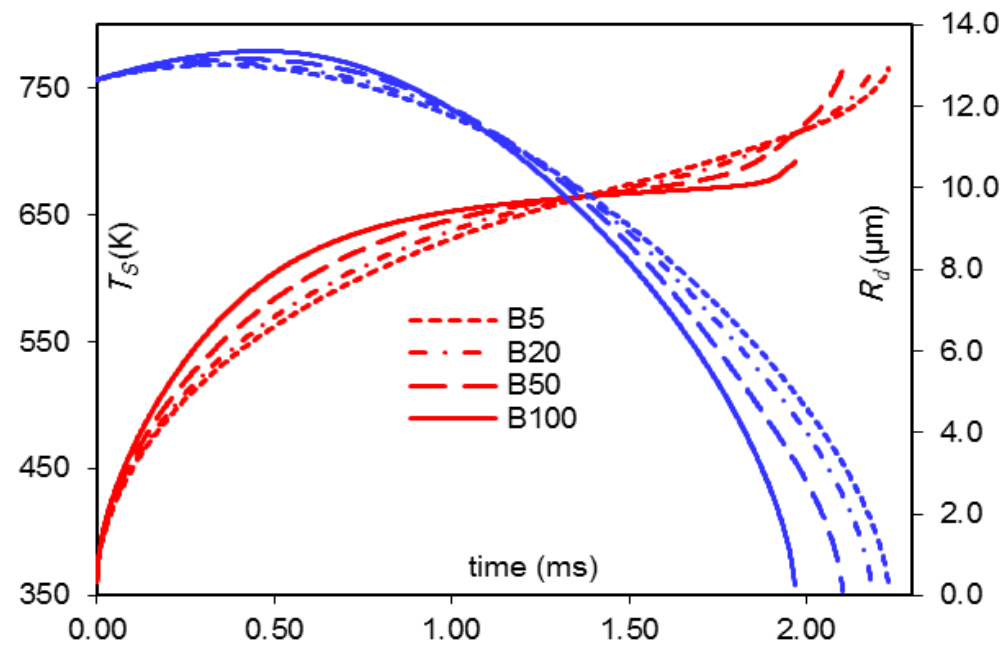

Figure 1. Droplet surface temperatures $T_{s}$ and radii $R_{d}$ versus time for four fractions of TME biodiesel fuel: B5, B20, B50 and $\mathrm{B} 100$. The droplet, of $12.66 \mu \mathrm{m}$ initial radius and $360 \mathrm{~K}$ initial temperature, is moving at $10 \mathrm{~m} / \mathrm{s}$ in still and dry air. The air pressure and temperature are 30 bar and $800 \mathrm{~K}$, respectively.

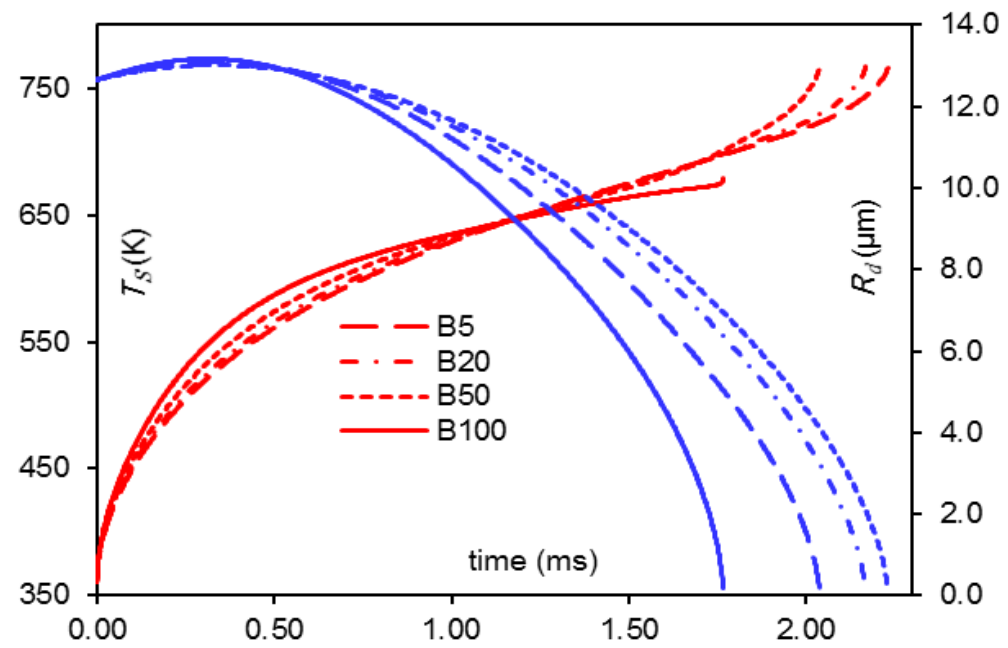

Figure 2. Droplet surface temperatures $T_{s}$ and radii $R_{d}$ versus time for four fractions of CME biodiesel fuel: $\mathrm{B} 5, \mathrm{~B} 20, \mathrm{~B} 50$ and B100, using the same ambient conditions and input parameters as in Figure 1. 


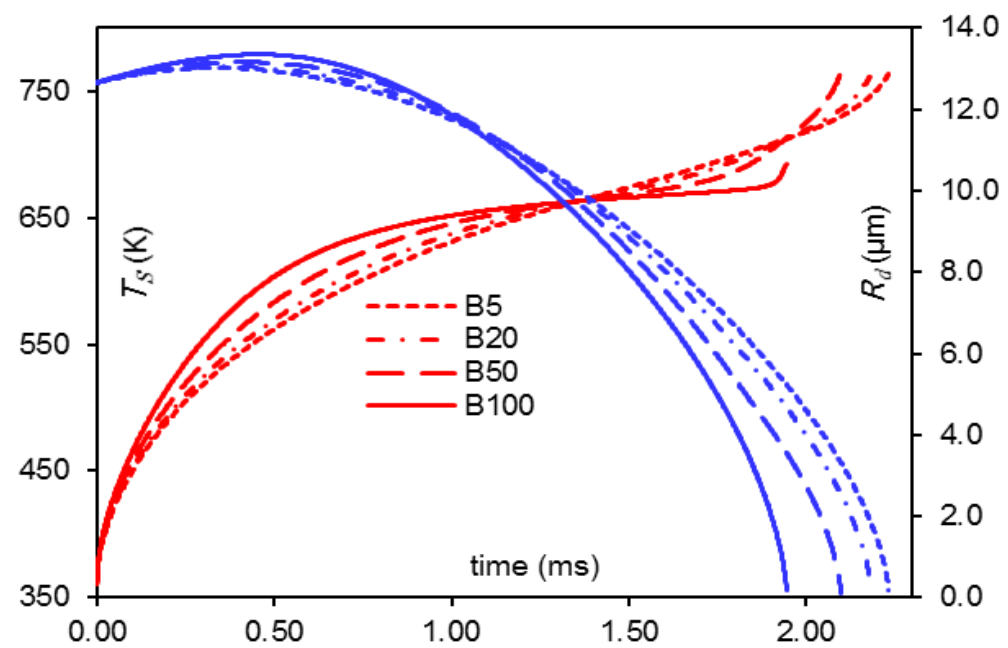

Figure 3. Droplet surface temperatures $T_{s}$ and radii $R_{d}$ versus time for four fractions of PME biodiesel fuel: B5, B20, B50 and B100, using the same ambient conditions and input parameters as in Figures 1 and 2.

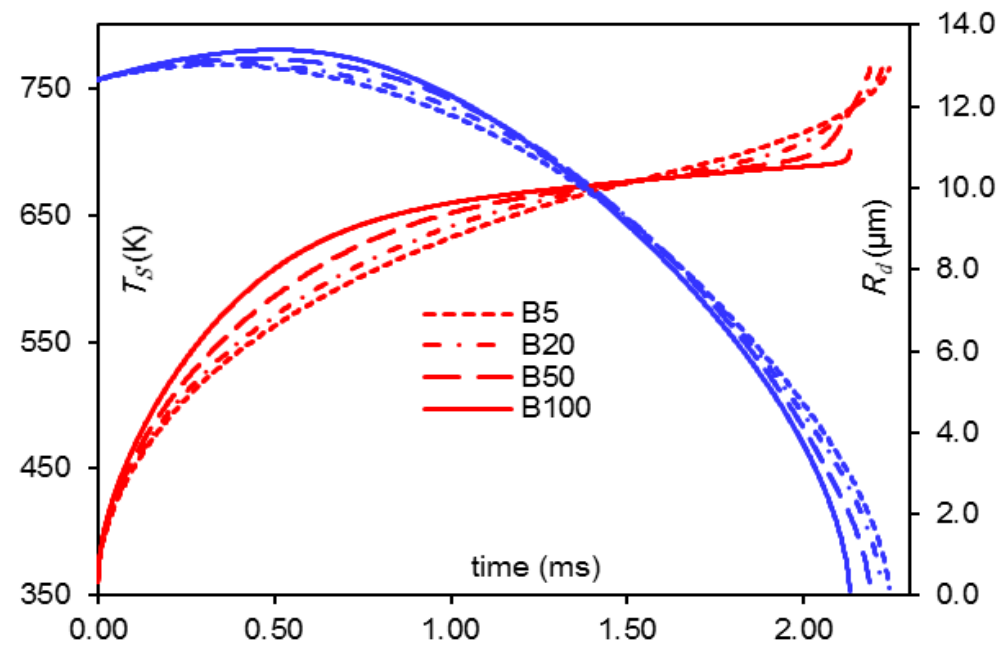

Figure 4. Droplet surface temperatures $T_{s}$ and radii $R_{d}$ versus time for four fractions of RME biodiesel fuel: B5, B20, B50 and B100, using the same ambient conditions and input parameters as in Figures 1-3.

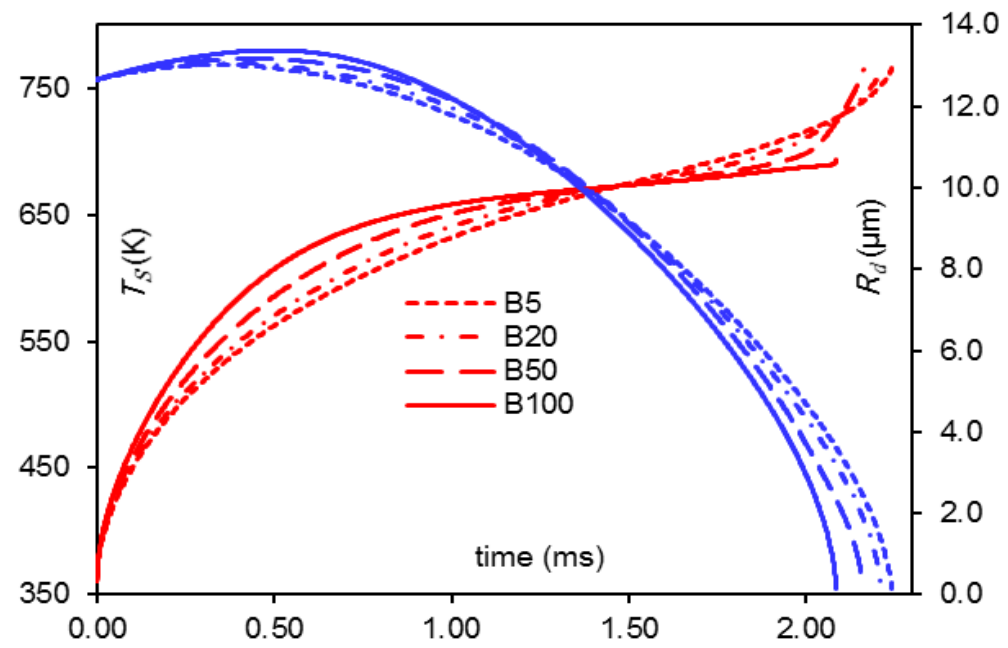

Figure 5. Droplet surface temperatures $T_{s}$ and radii $R_{d}$ versus time for four fractions of TGE biodiesel fuel: B5, B20, B50 and B100, using the same ambient conditions and input parameters as in Figures 1-4. 


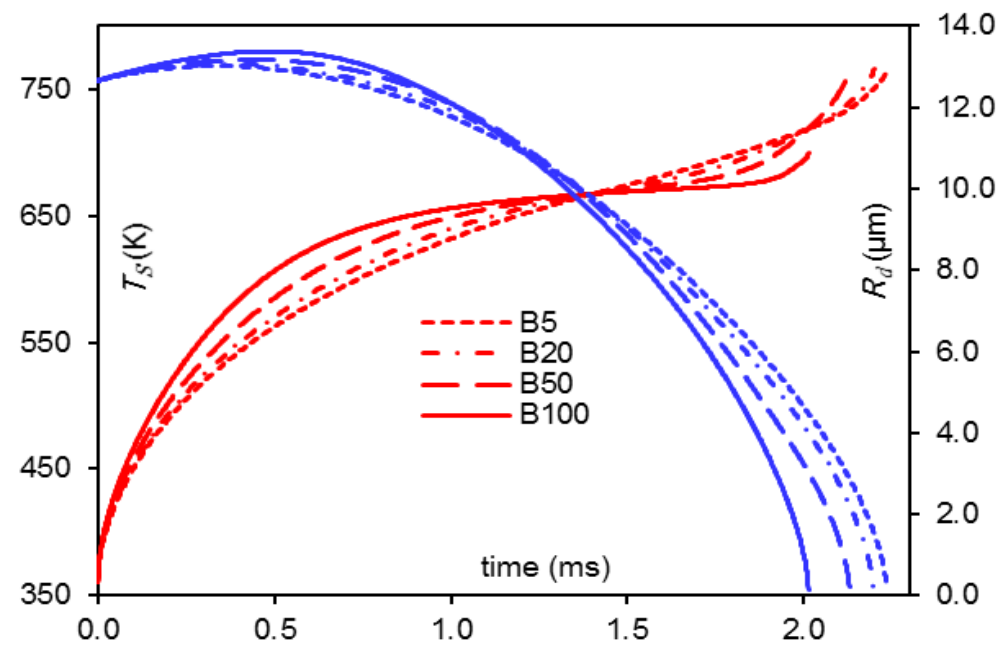

Figure 6. Droplet surface temperatures $T_{s}$ and radii $R_{d}$ versus time for four fractions of CAN biodiesel fuel: $\mathrm{B} 5, \mathrm{~B} 20, \mathrm{~B} 50$ and B100, using the same ambient conditions and input parameters as in Figures 1-5.

In Figures 1-6, one can see that increasing the concentration of biodiesel from B5 to B100 has a noticeable effect on the evolution of $R_{d}$ and $T_{s}$ for TME, CME, PME, RME, TGE, and CAN biodiesel fuels. In addition, the predicted surface temperature of the droplet for B100 is higher than that of B5 during the initial heating period. According to [10], the droplet break-up process can be enhanced as a result of the increase in droplet surface temperature. This can be attributed to the decrease in droplet surface tension. A full illustration of the results provided in Figure 1-6 are shown in Table 1. The droplet lifetimes of 19 types of biodiesel fuels mixtures with PD and their deviations from the one predicted for PD $(2.25 \mathrm{~ms})$ are presented in this table.

Table 1. Estimation of biodiesel fuel droplets lifetimes and their deviations compared with those of PD (2.25 ms) under the same conditions shown in Figures 1-8.

\begin{tabular}{|c|c|c|c|c|c|c|c|c|}
\hline \multirow{2}{*}{$\begin{array}{l}\text { Biodiesel } \\
\text { fuels }\end{array}$} & \multicolumn{2}{|c|}{ B100 } & \multicolumn{2}{|c|}{ B50 } & \multicolumn{2}{|c|}{ B20 } & \multicolumn{2}{|c|}{ B5 } \\
\hline & $\begin{array}{l}\text { Lifetime } \\
\text { (ms) }\end{array}$ & $\begin{array}{c}\text { Deviation } \\
(\%)\end{array}$ & $\begin{array}{l}\text { Lifetime } \\
\text { (ms) }\end{array}$ & $\begin{array}{c}\text { Deviation } \\
(\%)\end{array}$ & $\begin{array}{l}\text { Lifetime } \\
\text { (ms) }\end{array}$ & $\begin{array}{c}\text { Deviation } \\
(\%)\end{array}$ & $\begin{array}{l}\text { Lifetime } \\
\text { (ms) }\end{array}$ & $\begin{array}{c}\text { Deviation } \\
(\%)\end{array}$ \\
\hline TME & 1.967 & 12.58 & 2.102 & 6.58 & 2.184 & 2.93 & 2.232 & 0.80 \\
\hline LME & 1.995 & 11.33 & 2.114 & 6.04 & 2.190 & 2.67 & 2.234 & 0.71 \\
\hline BME & 1.943 & 13.64 & 2.089 & 7.16 & 2.180 & 3.11 & 2.232 & 0.80 \\
\hline CME & 1.765 & 21.56 & 2.036 & 9.51 & 2.166 & 3.73 & 2.229 & 0.93 \\
\hline PMK & 1.846 & 17.96 & 2.050 & 8.89 & 2.169 & 3.60 & 2.230 & 0.89 \\
\hline PME & 1.944 & 13.60 & 2.097 & 6.80 & 2.183 & 2.98 & 2.232 & 0.80 \\
\hline SFE & 1.980 & 12.00 & 2.122 & 5.69 & 2.195 & 2.44 & 2.235 & 0.67 \\
\hline PTE & 2.052 & 8.80 & 2.138 & 4.98 & 2.199 & 2.27 & 2.236 & 0.62 \\
\hline CSE & 2.014 & 10.49 & 2.128 & 5.42 & 2.197 & 2.36 & 2.236 & 0.62 \\
\hline CNE & 2.002 & 11.02 & 2.128 & 5.42 & 2.197 & 2.36 & 2.236 & 0.62 \\
\hline SNE & 2.011 & 10.62 & 2.132 & 5.24 & 2.200 & 2.22 & 2.237 & 0.58 \\
\hline SME & 1.981 & 11.96 & 2.127 & 5.47 & 2.198 & 2.31 & 2.236 & 0.62 \\
\hline RME & 2.131 & 5.29 & 2.188 & 2.76 & 2.222 & 1.24 & 2.242 & 0.36 \\
\hline LNE & 1.991 & 11.51 & 2.141 & 4.84 & 2.206 & 1.96 & 2.239 & 0.49 \\
\hline TGE & 2.085 & 7.33 & 2.160 & 4.00 & 2.211 & 1.73 & 2.240 & 0.44 \\
\hline HME1 & 2.022 & 10.13 & 2.138 & 4.98 & 2.203 & 2.09 & 2.237 & 0.58 \\
\hline HME2 & 1.994 & 11.38 & 2.135 & 5.11 & 2.202 & 2.13 & 2.238 & 0.53 \\
\hline CAN & 2.014 & 10.49 & 2.130 & 5.33 & 2.199 & 2.27 & 2.236 & 0.62 \\
\hline WCO & 2.002 & 11.02 & 2.121 & 5.73 & 2.194 & 2.49 & 2.235 & 0.67 \\
\hline
\end{tabular}


As can be seen from Table 1, the droplet lifetime for B100 of RME fuel is $6 \%$ less than that of PD. This reduction does not exceed $0.4 \%$ for the B5 fuel blend for the same fuel. Also, droplet lifetime of TGE biodiesel fuel droplet are noticeably close to that of PD droplet; it is less than $8 \%$ and $0.5 \%$ for B100 and B5 mixtures, respectively. The maximum deviation in droplet lifetimes for these fuels are up to 21. 6\% (B100 CME), which cannot be sacrificed in any engineering application, and it is always higher than $5.29 \%$ (RME) compared to PD, which may be tolerated in some limited engineering applications.

A typical example of time evolutions of mass fractions at the surface of droplets $\left(Y_{\text {lis }}\right)$ of selected nine species of B50 fuel mixture of diesel with RME and CME are shown in Figures 7 and 8, respectively.

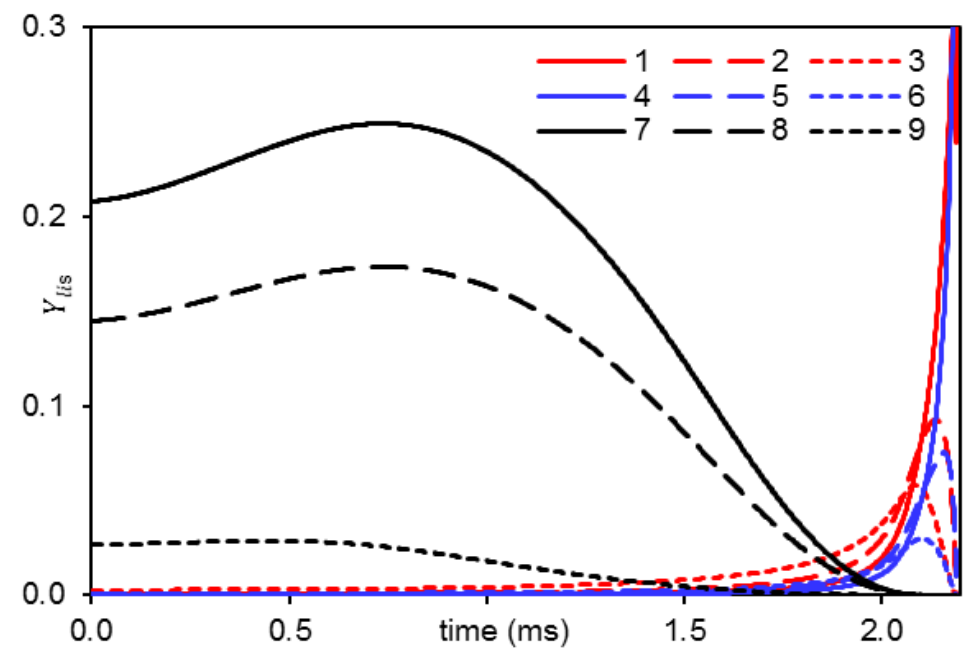

Figure 7. The liquid mass fractions at the surface of droplet $\left(Y_{l i s}\right)$ versus time for selected 9 components of 106 components of B50 (50\% diesel hydrocarbons and 50\% rapeseed methyl ester (RME)) fuel mixture. The red coloured curves, 1, 2 and 3, refer to alkane hydrocarbons of $\mathrm{C}_{23} \mathrm{H}_{48}, \mathrm{C}_{25} \mathrm{H}_{52}$ and $\mathrm{C}_{27} \mathrm{H}_{56}$, respectively; the blue curves, 4,5 and 6 , refer to cycloalkane hydrocarbons of $\mathrm{C}_{23} \mathrm{H}_{46}, \mathrm{C}_{25} \mathrm{H}_{50}$ and $\mathrm{C}_{27} \mathrm{H}_{54}$, respectively; and the black curves, 7,8 and 9 , refer to rapeseed methyl esters of $\mathrm{C}_{19} \mathrm{H}_{36} \mathrm{O}_{2}, \mathrm{C}_{19} \mathrm{H}_{34} \mathrm{O}_{2}$ and $\mathrm{C}_{17} \mathrm{H}_{34} \mathrm{O}_{2}$, respectively, under the same conditions used in Figures 1-6.

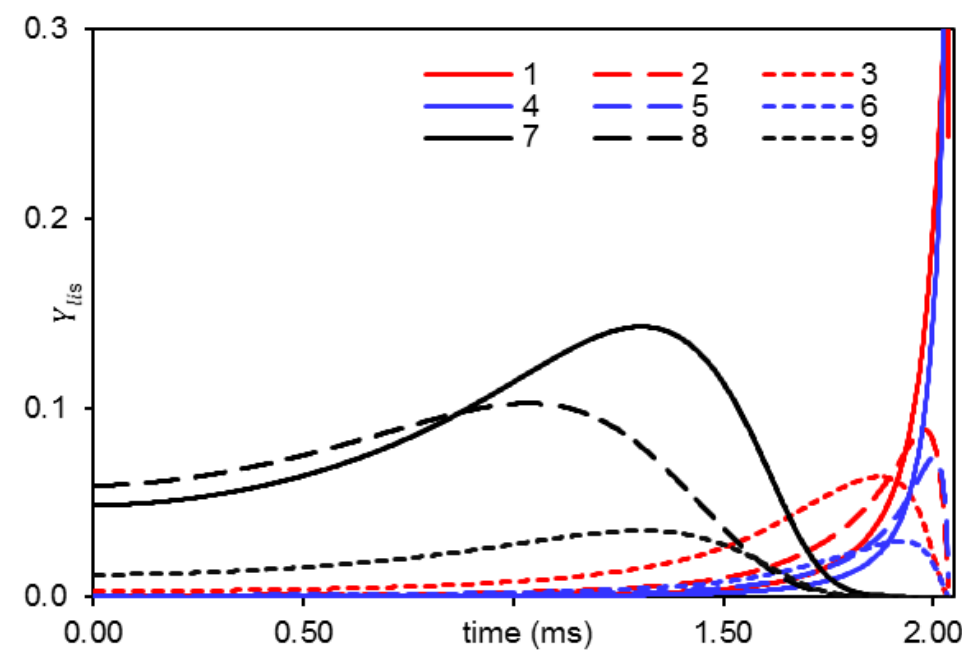

Figure 8. The liquid mass fractions at the surface of droplet $\left(Y_{l i s}\right)$ versus time for selected 9 components of 106 components of B50 (50\% diesel hydrocarbons and 50\% coconut methyl ester (CME)) fuel mixture. The red coloured curves 1, 2 and 3, refer to alkane hydrocarbons of $\mathrm{C}_{27} \mathrm{H}_{56}, \mathrm{C}_{25} \mathrm{H}_{52}$ and $\mathrm{C}_{23} \mathrm{H}_{48}$, respectively; and the blue curves 4,5 and 6 , refer to cycloalkane

hydrocarbons of $\mathrm{C}_{27} \mathrm{H}_{54}, \mathrm{C}_{25} \mathrm{H}_{50}$ and $\mathrm{C}_{23} \mathrm{H}_{46}$, respectively; and the black curves, 7, 8 and 9, refer to rapeseed methyl esters of $\mathrm{C}_{19} \mathrm{H}_{36} \mathrm{O}_{2}, \mathrm{C}_{19} \mathrm{H}_{34} \mathrm{O}_{2}$ and $\mathrm{C}_{17} \mathrm{H}_{34} \mathrm{O}_{2}$, respectively, under the same conditions used in Figures 1-7.

As can be seen from Figures 7 and 8, the diffusion of mass fractions of components at the surface of droplets are typical and similar to those presented in previous studies. The mass fractions of the heavy components, e.g. $\mathrm{C}_{27} \mathrm{H}_{56}$, $\mathrm{C}_{27} \mathrm{H}_{54}(1,4)$, increase with time at the expense of the lighter ones. This result is compatible with the findings presented in $[7,11,18]$.

In some previous studies (e.g. [10,17]) the heating and evaporation of PD droplets and their comparison to the results of diesel-biodiesel blends were analysed. For instance, in [17] the droplet lifetime for B100 of WCO was 
shown to be $11 \%$ less than that of PD. While in [10], the droplet lifetime for B100 of SME fuel was shown to be $6 \%$ less than that for PD. In this study, similar trends were predicted for the same fuels. This prediction, however, was different for the other types of biodiesel fuel presented in this paper. For example, the B100 droplet lifetimes for CME and PMK biodiesel fuels showed deviations of $21.6 \%$ and $18 \%$, respectively, from that of PD.

A general trend shows that droplets' lifetimes of all 19 types of B5 diesel-biodiesel blends that are used in this study deviate with less than $1 \%$ from the one predicated for PD droplets. This concludes the possibility of labelling dieselbiodiesel blends, with up to about $5 \%$ biodiesel concentration, without modifying the automotive system achievable. For some fuel blends (e.g. B20 RME, TGE, LNE, and HME1), this deviation (up to $2 \%$ ) is still relatively negligible to mix higher biodiesel concentrations (e.g. $20 \%$ biodiesel and $80 \%$ diesel fuels) without losing the main feature of these processes (i.e. droplet lifetime).

The difference in thermodynamic and transport properties between hydrocarbons and methyl esters is the main reason for the influence of biodiesel fuel fractions on the heating and evaporation of diesel fuel droplets. For instance, when increasing the biodiesel fractions, the droplet surface temperature tends to reach a plateau during the evaporation process, which is similar to the case of single component model (see [7,13]). Also, the significance of such behaviour can change depending on the input parameters and ambient conditions.

\section{Conclusion}

In this analysis, the discrete component model was used to analyse the heating and evaporation of blended dieselbiodiesel fuel droplets using 19 types of biodiesel fuel. The full compositions of diesel and biodiesel fuels were considered. The diesel fuel consisted of 98 hydrocarbons and the 19 biodiesel fuels, TME, LME, BME, CME, PMK, PME, SFE, PTE, CSE, CNE, SNE, SME, RME, LNE, TGE, HME1, HME2, CAN and WCO, consisted of 11, 8, 14, $8,11,10,4,8,7,8,7,7,8,6,7,13,7,12$ and 14 components of methyl esters, respectively.

The effect of increasing biodiesel fuel concentration on the evolutions of droplet surface temperature and evaporation time was clearly illustrated. The predicted B5 fuel droplet lifetimes for the 19 types of biodiesel fuel were only $1 \%$ less than that of pure diesel fuel (PD). The RME biodiesel fuel droplets were observed to have lifetimes close to that of PD, where their predicted lifetimes for B5 and B100 droplets were up to $6 \%$ and $0.4 \%$, respectively, less than the one estimated for PD droplet.

To conclude, the B5 fuel droplet lifetimes for all 19 types of biodiesel fuels used in this study are almost identical to the one predicted for PD; i.e. diesel fuel can be possibly blended with up to $5 \%$ biodiesel fuel without any noticeable effect on the evolutions of their radii or temperatures.

\section{Acknowledgment}

The authors are grateful to the Centre for Mobility and Transport - Coventry University for financial support.

$\begin{array}{ll}\text { Nomenclature } \\ \text { B\# } & \text { \#\% biodiesel/diesel fraction } \\ \text { BME } & \text { butter methyl ester } \\ \text { CAN } & \text { canola methyl ester } \\ \text { CME } & \text { coconut methyl ester } \\ \text { CNE } & \text { corn methyl ester } \\ \text { CSE } & \text { cottonseed methyl ester } \\ \text { DCM } & \text { discrete component model } \\ \text { ED } & \text { effective diffusivity } \\ \text { ETC } & \text { effective thermal conductivity } \\ \text { FAME } & \text { fatty acid methyl ester } \\ \text { HME1 } & \text { hempseed-oil, produced in Ukraine } \\ \text { HME2 } & \text { hempseed-oil, produced in the EU } \\ \text { LME } & \text { lard methyl ester } \\ \text { LNE } & \text { linseed methyl ester } \\ \text { PD } & \text { pure diesel fuel } \\ \text { PME } & \text { palm methyl ester } \\ \text { PMK } & \text { palm kernel methyl ester } \\ \text { PTE } & \text { peanut methyl ester } \\ \text { Re } & \text { Reynolds number } \\ \text { RME } & \text { rapeseed methyl ester } \\ \text { Sc } & \text { Schmidt number } \\ \text { SFE } & \text { safflower methyl ester } \\ & \end{array}$

$\begin{array}{ll}\text { Sh } & \text { Sherwood number } \\ \text { SME } & \text { soybean methyl ester } \\ \text { SNE } & \text { sunflower methyl ester } \\ \text { TGE } & \text { tung methyl ester } \\ \text { TME } & \text { tallow methyl ester } \\ \text { WCO } & \text { waste cooking oil }\end{array}$

\section{Symbols}

$B_{M} \quad$ Spalding mass transfer number

$c \quad$ heat capacity [ $\left.\mathrm{J}_{\mathrm{kg}} \mathrm{K}^{-1} \mathrm{~K}^{-1}\right]$

$C_{F} \quad$ friction drag coefficient

$D \quad$ diffusion coefficient $\left[\mathrm{m}^{2} \mathrm{~s}^{-1}\right]$

$k \quad$ thermal conductivity [W. $\mathrm{m}^{-1} \mathrm{~K}^{-1}$ ]

$\dot{m} \quad$ evaporation rate [kg. $\left.\mathrm{s}^{-1}\right]$

$p \quad$ gas pressure [bar]

$R \quad$ radius $[\mu \mathrm{m}]$

$\rho \quad$ density $\left[\mathrm{kg} \cdot \mathrm{m}^{-3}\right]$

$t \quad$ time [ms]

$T \quad$ temperature $[\mathrm{K}]$

$u \quad$ velocity $\left[\mathrm{m} \cdot \mathrm{s}^{-1}\right]$

$v \quad$ kinematic viscosity $\left[\mathrm{m}^{2} \mathrm{~s}^{-1}\right]$

$X \quad$ molar fraction 


$\begin{array}{llll}\chi & \text { recirculation coefficient } & i & \text { liquid species } \\ Y & \text { mass fraction } & \text { iso } & \text { isothermal process } \\ & & g & \text { gas } \\ \text { Subscripts } & l & \text { liquid } \\ \text { eff } & \text { effective thermal conductivity } & s & \text { droplet surface } \\ d \quad & \text { droplet } & v & \text { vapour }\end{array}$

\section{References}

[1] Lapuerta, M., Armas, O., and Rodríguez-Fernández, J., 2008, Prog. Energy Combust. Sci., 34(2), pp. $198-223$.

[2] Meher, L. C., Vidya Sagar, D., and Naik, S. N., 2006, Renew. Sustain. Energy Rev., 10(3), pp. $248-268$.

[3] Pan, K.-L., Li, J.-W., Chen, C.-P., and Wang, C.-H., 2009, Combust. Flame, 156(10), pp. 1926-1936.

[4] US Department of Energy: Energy Efficiency and Renewable Energy, "Biodiesel Blends" [Online]. Available: http://www.afdc.energy.gov/fuels/biodiesel_blends.html. [Accessed: 19-Mar-2017].

[5] Sazhin, S. S., 2017, Fuel, 196, pp. 69-101.

[6] Al Qubeissi, M., 2015, Heating and Evaporation of Multi-Component Fuel Droplets, WiSa, Germany.

[7] Sazhin, S. S., Al Qubeissi, M., Nasiri, R., Gun'ko, V. M., Elwardany, A. E., Lemoine, F., Grisch, F., and Heikal, M. R., 2014, Fuel, 129, pp. 238-266.

[8] Al Qubeissi, M., Sazhin, S. S., Crua, C., Turner, J., and Heikal, M. R., 2015, Fuel, 154, pp. 308-318.

[9] Sazhin, S. S., Al Qubeissi, M., Kolodnytska, R., Elwardany, A. E., Nasiri, R., and Heikal, M. R., 2014, Fuel, 115, pp. 559-572.

[10] Al Qubeissi, M., Sazhin, S. S., and Elwardany, A. E., 2017, Fuel, 187, pp. 349-355.

[11] Al Qubeissi, M., and Sazhin, S. S., 2016, 27th European Conference on Liquid Atomization and Spray Systems, Brighton, UK, p. 179.

[12] Sazhin, S. S., 2014, Droplets and Sprays, Springer, London.

[13] Elwardany, A. E., Gusev, I. G., Castanet, G., Lemoine, F., and Sazhin, S. S., 2011, At. Sprays, 21(11), pp. $907-931$.

[14] Abramzon, B., and Sazhin, S. S., 2006, Fuel, 85(1), pp. 32-46.

[15] Abramzon, B., and Sirignano, W. A., 1989, Int. J. Heat Mass Transf., 32(9), pp. 1605-1618.

[16] Sirignano, W. A., 1999, Fluid Dynamics and Transport of Droplets and Sprays, Cambridge University Press, Cambridge, U.K.

[17] Al Qubeissi, M., Sazhin, S. S., de Sercey, G., and Crua, C., 2014, 26th European Conference on Liquid Atomization and Spray Systems, University of Bremen, Bremen, Germany. 